\title{
Erratum to: Cooperative Knowledge Processing for Engineering Design
}

\author{
Arthur B. Baskin ${ }^{1}$, George Kovács ${ }^{2}$, and Gianni Jacucci ${ }^{3}$ \\ 1 Intelligent Information Technologies, Corp., Urbana, IL, USA \\ 2 Computer and Automation Research Institute, Budapest, Hungary \\ 3 University of Trento, Rovereto, Italy
}

\section{Erratum to:}

\section{A.B. Baskin et al. (Eds.) \\ Cooperative Knowledge Processing \\ for Engineering Design \\ DOI: $10.1007 / 978-0-387-35357-9$}

The book was inadvertently published with an incorrect name of the copyright holder. The name of the copyright holder for this book is: (c) IFIP International Federation for Information Processing. The book has been updated with the changes.

The updated original online version for this book can be found at DOI: 10.1007/978-0-387-35357-9 